\title{
Bile Stained Vomiting in Neonates: Radiological and Surgical Correlation
}

\author{
MOHAMMED ZAKI A. MOURAD, M.D.*; MOHAMED Y. BATIKHE, M.D.**; \\ ASHRAF ABOU-TALEB, M.D.*** and HISHAM ABDEL GHANY, M.D.* \\ The Departments of of Radiology*, Pediatric Surgery Unit, Department of Surgery** and Pediatrics***, \\ Faculty of Medicine, Sohag University, Egypt
}

\begin{abstract}
Background: Bile stained vomiting in neonates is frequently encountered clinical symptom in pediatric practice. It is very important to examine them and exclude or confirm surgical condition.

Aim of Study: This work is advocated to illustrate the spectrum of radiological findings in neonates with bile stained vomiting and correlate them with surgical data.

Patients and Methods: All included neonates presented with bile stained vomiting were referred to Diagnostic Radiology Department at Sohag University Hospitals. Abdominal X-ray, abdominal ultrasound, Doppler and contrast imaging were done to identify the surgical causes of bilious vomiting with clinical and surgical correlation. The patients were treated surgically in Pediatric Surgery Unit at Sohag University Hospitals. Patients with bilious vomiting caused by nonsurgical causes were excluded.

Results: Our study included 31 bile stained vomiting neonates with age range from one day to 30 days and with male sex predominance ( 17 boys and 14 girls). Four patients were found to have necrotizing enterocolitis, 5 cases with mid-gut volvulus, 3 cases were found to have distal duodenal atresia, one case with duodenal stenosis, 5 cases with jejunal atresia, 4 cases with ileal atresia, 2 cases with congenital bands, 2 cases with complicated congenital inguinal hernias, 2 cases with meconium plug, 1 case with neonatal intussusception, 1 case with iatrogenic clamping of umbilical hernia and 1 case with anal stenosis. Imaging techniques were diagnostic in most of the cases and correlate with surgical findings.

Conclusion: Bile stained vomiting in the newborn usually indicative of surgical conditions and needs surgical consultation. Imaging studies are of utmost important to investigate and diagnose these cases before surgery.
\end{abstract}

Key Words: Bile stained vomiting - Sonography - Ultrasound - Contrast imaging - Newborn surgery.

Correspondence to: Dr.: Mohammed Zaki A. Mourad, E-Mail: zakifm2000@yahoo.com

\section{Introduction}

BILE stained vomiting in the newborn is a very important clinical data to be considered. It usually denotes a serious problem in the neonatal period. There are many surgical causes to be investigated [1-6]. The obstruction is beyond the papilla of Vater. Intestinal atresia is the most significant cause in bilious vomiting the newborn. It may be at the level of the distal duodenum, jejunum or may be at the ileal level [7-10]. Mid-gut volvulus is a major cause in a newborn with bilious vomiting because of serious complication of intestinal ischemia [11,12]. Other causes of intestinal obstruction such as incarcerated inguinal hernia [13] or congenital bands [14] must be considered. Necrotizing enterocolitis is not a rare cause of bile stained vomitus in neonates [15]. There are also non-surgical causes of bilious vomiting such sepsis, renal or toxic agents [16].

Radiology has a major role in diagnosis of the specific cause of bilious vomiting in the newborn especially with sonography with Doppler and contrast imaging $[\mathbf{1 7 , 1 8}]$. Urgent surgical management of these neonates is mandatory to decrease morbidity and mortality among this group of patients.

The aim of this study to illustrate the spectrum of radiological findings of different causes of bile stained vomiting with surgical correlation.

\section{Patients and Methods}

All neonates with bile stained vomiting were referred to Diagnostic Radiology Department at

\footnotetext{
Abbreviations:

US : Ultrasonography.

DA : Duodenal Atresia

JIA : Jejuno-Ileal Atresia.
} 
Sohag University Hospitals from July 2017 to July 2019 to investigate the surgical causes of bile stained vomiting were included. Written informed consent was taken from the patients parents in accord with the ethical standards of the institutional committee.

After complete clinical data with pre-natal history at Pediatric Department, erect abdomen Xray was taken to show distribution of abdominal air. Color Doppler Sonography using linear highfrequency probe (10-14MHz), Toshiba Aplio system was the second step to do. Abdominal sonography was done with relaxed abdomen. After full abdominal and pelvis examination, we traced the GIT from the stomach downwards. Dilated stomach, duodenum, small bowel was noticed to determine the level of obstruction. Doppler sonography were applied especially in compromised vascularity cases as in midgut volvulus and incarcerated inguinal hernia.

Contrast follow through was done using Ultravist as needed. About $7-10 \mathrm{~cm}$ contrast material was introduced via Ryle tube. Then; we follow the contrast to observe the distribution of contrast and level of obstruction.

All neonates were fully observed pre- operatively in Neonatal Care Unit. The patients were managed surgically in Pediatric Surgery Unit at Sohag University Hospitals and private sectors. Final diagnosis was established during laparotomy. Then; radiographic findings are compared with operative data.

All patients referred with bile stained vomiting caused by non-surgical causes were managed nonoperatively and excluded from this study.

\section{Results}

Our work included 31 neonates with bile stained vomiting were managed surgically. Age range was from 1 day to 30 days. They were 17 males and 14 females. The surgical causes of the neonatal bile stained vomiting in our series were necrotizing enterocolitis, found in 4 neonates, midgut volvulus in 5 cases, distal duodenal atresia in 3 patients, duodenal stenosis in one case, Jejunal atresia in 5 cases, ileal atresia in 4 cases, congenital bands in 2 cases, complicated congenital inguinal hernia in 4 cases, meconium plug in 2 cases, neonatal intussusception in one case and finally iatrogenic clamping of umbilical hernia in one case and finally neonatal anal stenosis in one case (Table 1).
As regards the four neonates with necrotizing enterocolitis which found in our work; the patients came with abdominal distension and bile stained vomiting. Pneumo-peritoneum was found in 2 cases on erect abdominal X-ray. Turbid fluid collection in 2 cases and mural and hepatic air in 3 cases at sonography, surgery confirmed the diagnosis of necrotizing enterocolitis with surgical repair of the perforations Figs. $(1,2)$.

Our study described 5 cases with mid-gut volvulus Figs. $(3,4)$ presented with bile stained vomiting. Plain X-ray was not significant. Abdominal sonography and Doppler revealed the classical stigmata of mid-gut volvulus and they include; whirl pool sign, dilated duodenum and dilated splenic veins. On contrast study; dilated duodenum and central irregular filling defect are found. Surgery was performed in all cases and untwisting of the volvulus was performed to relieve the obstruction.

Three cases of distal duodenal atresia presented with bile stained vomiting were encountered in our series. Double air bubble sign were observed in plain films with gasless abdomen beyond this level. On sonography; dilated duodenum is noted with gasless abdomen beyond the obstruction. Contrast examination revealed distal duodenal obstruction and the contrast could not pass beyond this level. Surgical management was done to these cases Fig. (5).

Congenital duodenal stenosis was seen in one case. The baby came with bile stained vomiting. Few air fluid levels are seen on plain film. Contrast study illustrated dilated duodenum with minimal spill of contrast into the small intestine. Surgical exploration confirmed the duodenal obstruction and revealed incomplete congenital web Fig. (6).

As regards jejunal atresia ( 5 cases); the neonates were presented with bile stained vomiting. Few air-fluid levels were observed on plain X-ray. Sonography demonstrated few dilated intestinal loops with fluid. Contrast follow through were done to these cases and illustrated jejunal obstruction. Surgical management confirmed the diagnosis with surgical repair Fig. (7).

Ileal atresia was found in 4 cases. They presented with abdominal distension and bile stained vomiting. Multiple air-fluid levels were noted on plain X-ray Abdominal sonography revealed many dilated loops. Contrast follow through documented the ileal level of obstruction. Surgical resections 
of the atresia with end to end anastomosis were performed to those neonates Fig. (8).

Neonatal abdominal obstruction caused by congenital band found in one case in this study. The patient presented with bile stained vomiting and abdominal distension. Multiple air fluid levels were seen on erect abdomen X-ray. Sonography demonstrated dilated intestinal loops. This case was finally diagnosed at surgery that has congenital band and treated accordingly.

Complicated inguinal hernia by incarceration and obstruction were encountered in 2 cases in this series. The patient comes with inguino-scrotal swelling and bile stained vomiting. Plain erect abdominal X-ray revealed intestinal obstruction. Soft tissue sonography of the inguino-scrotal region demonstrated inguinal hernia containing intestinal loops. Doppler sonography showed the good vascularity of the contents. Urgent hernial repair were done to these cases and save the viability of the hernial contents. One of them was perforated at surgery Fig. (9).

Two of our neonates diagnosed as intestinal obstruction caused by inspissated meconium causing intestinal ileus. Plain film revealed multiple air fluid levels. Meconium plugs filling defects appeared on contrast study. These neonates treated non-surgically by repeated enema Fig. (10).

This work includes a rare cause of intestinal obstruction in neonates which is intussusception. The newborn presented by bile stained vomiting. On sonography; short central intussusception was observed with dilated small intestinal loops proximal to it. Surgical management was done to this case Fig. (11).

Iatrogenic clamping of umbilical hernia was encountered in one case. The neonate came with bilious vomiting. Multiple air-fluid levels are seen in plan X-ray. Sonography revealed dilated intestinal loops tapered at the umbilicus. Urgent surgery was done with end to end anastomosis after excision of the clamped part.

Anal stenosis was found in one case in our study. The baby came with bile stained vomiting after unsuccessful trial of anal dilatation. Plain-Xray suggests the diagnosis in addition to the history. This case was treated by surgical repair Fig. (12).

Post-operative care was done in intensive care unit. All cases were observed for temperature, body fluid and incision care.
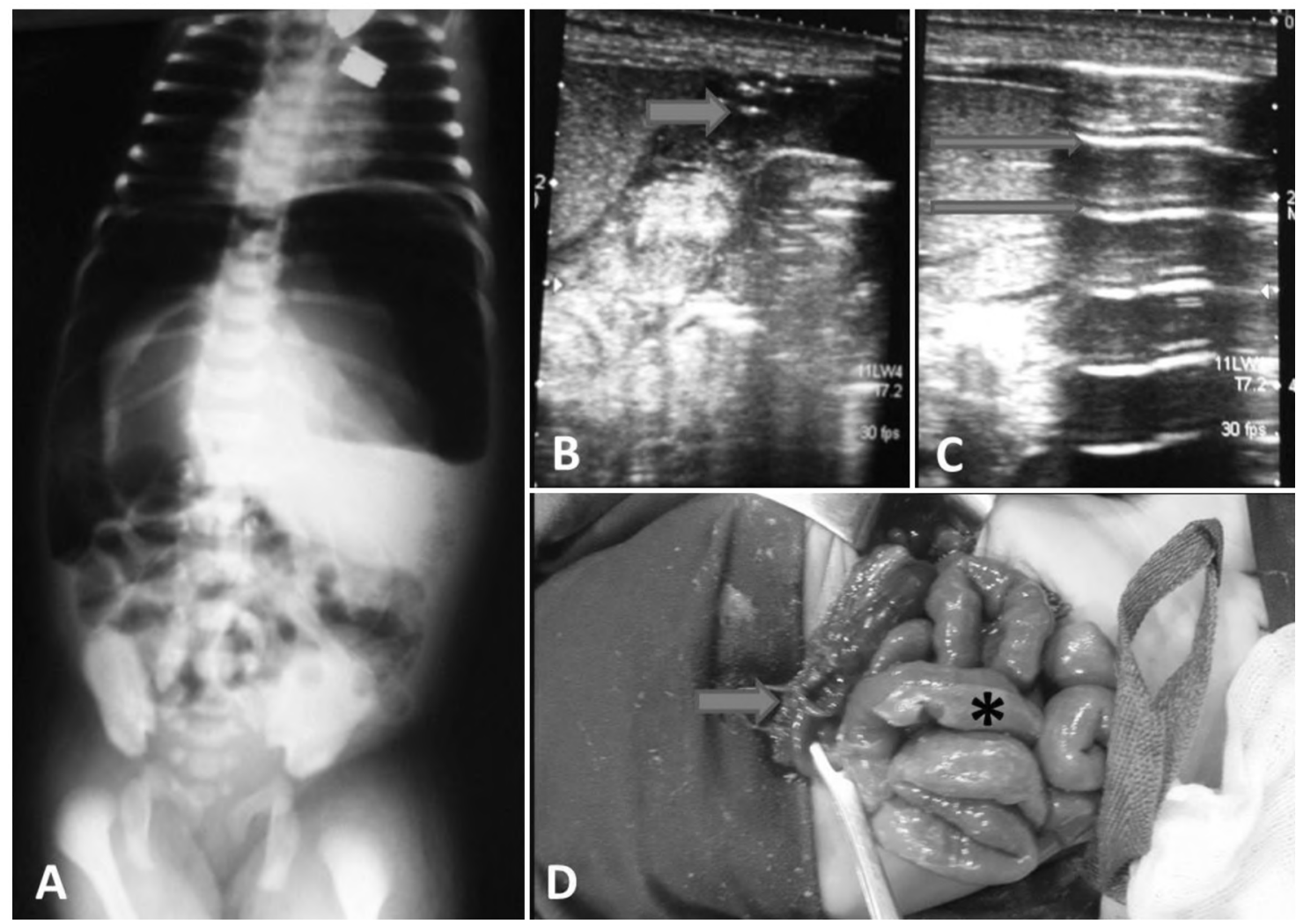

Fig. (1): A neonate with advanced necrotizing enterocolitis (A) Plain X-ray erect abdomen shows very large amount of air under diaphragm. (B) Sonography image showing the fluid collection. (C) Sonography image showing echo-artefacts due to pneumo-peritoneum. (D) Surgical photo showing the perforation (arrow) and pyogenic membrane (*). 

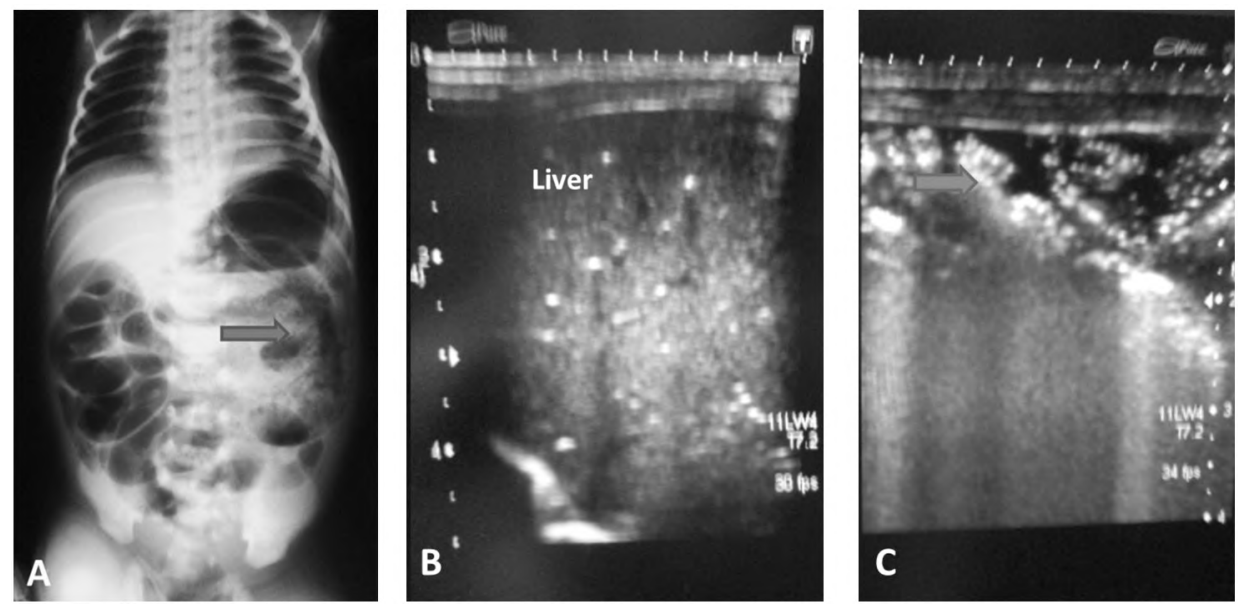

Fig. (2): A neonate with necrotizing enterocolitis (A) Plain X-ray erect abdomen showing intestinal wall air (arrow). (B) Sonography image showing the parenchymal hepatic air. (C) Sonography image illustrating intestinal wall air (arrow).
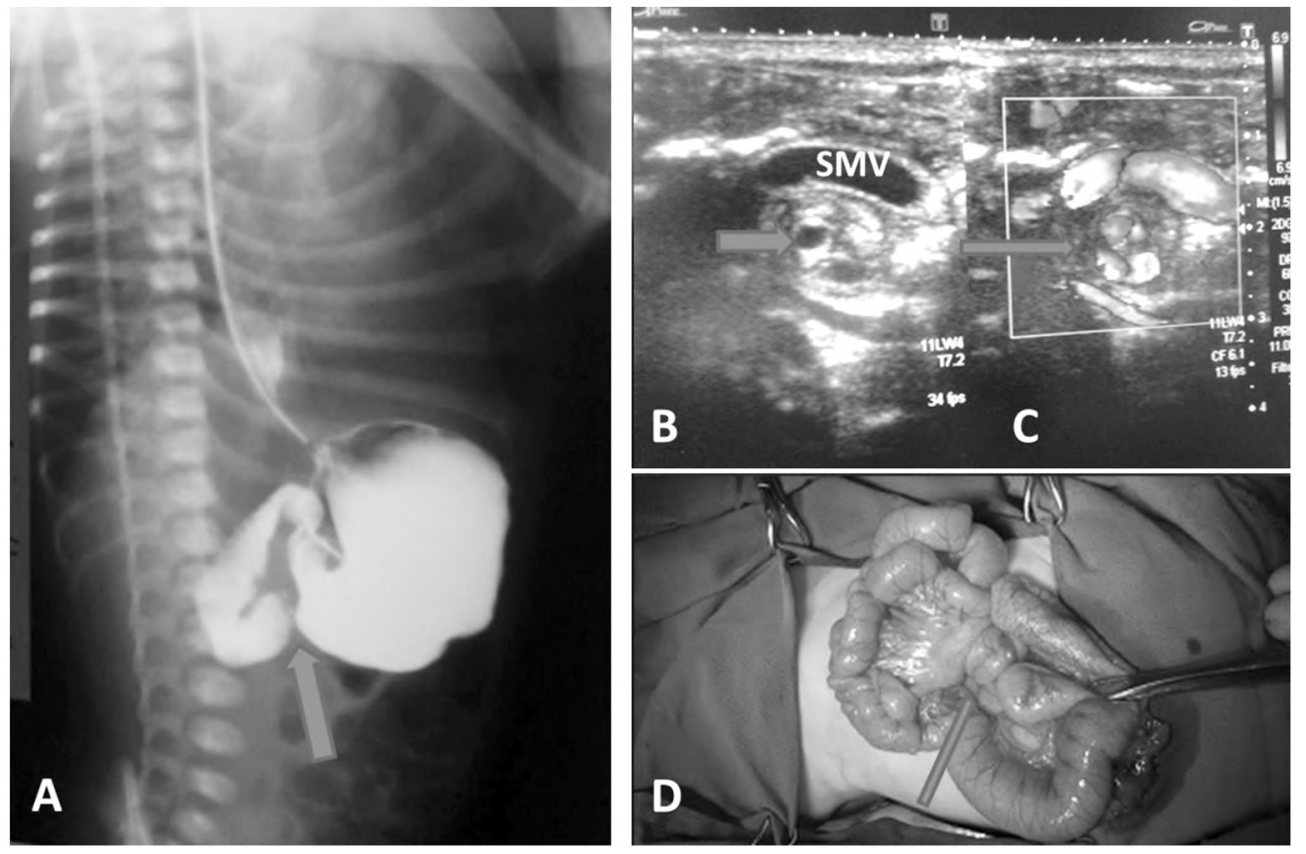

Fig. (3): A neonate with Mid-gut volvulus (A) Contrast oblique image of the abdomen illustrating duodenal obstruction. (B) Sonography image showing whirl pool sign (arrow) and dilated superior mesenteric vein (SMV). (C) Color Doppler image demonstrating wrapped superior mesenteric vein around the superior mesenteric artery. (D) Surgical photo showing the site of volvulus (arrow).
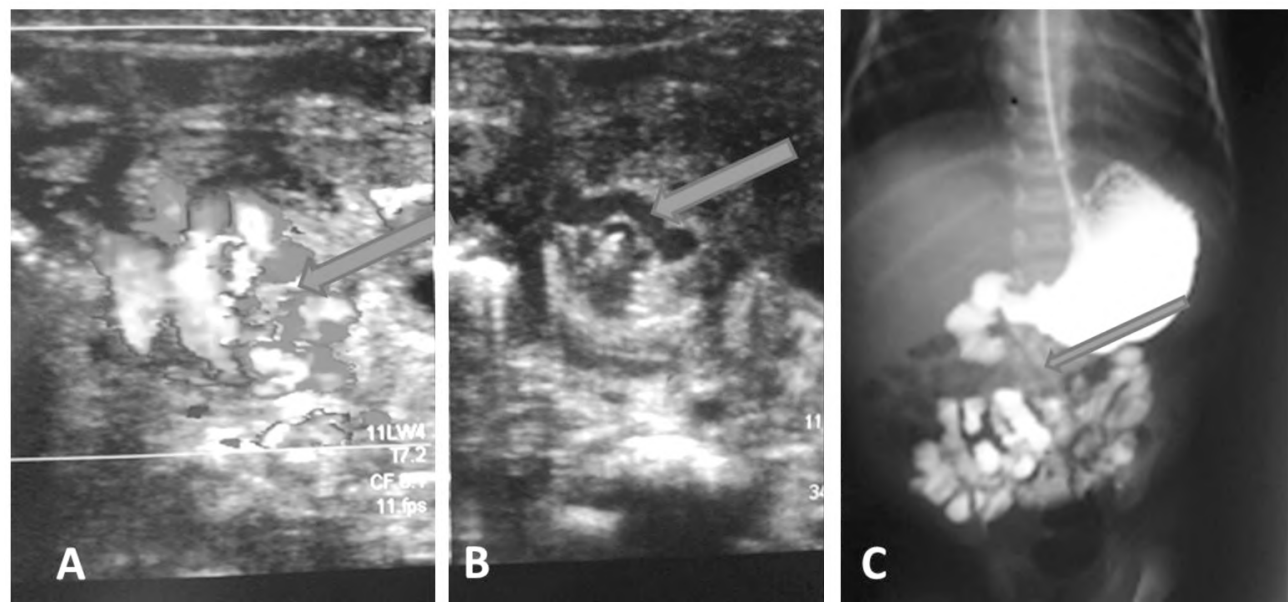

Fig. (4): A neonate with Mid-gut volvulus (A) Color Doppler image showing the wrapped vessels (arrow) (B) Sonography image showing whirl pool sign (arrow) (C) Contrast meal and follow through denoting the site of mid-gut volvulus (arrow). 

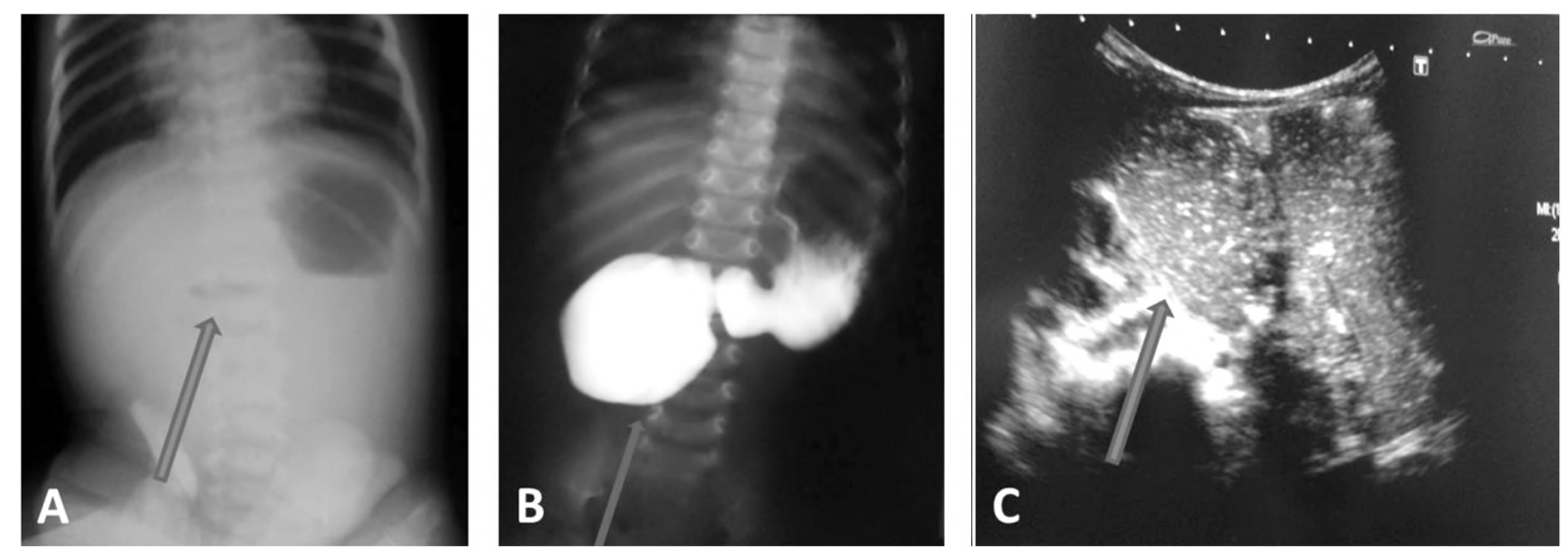

Fig. (5): A neonate with duodenal atresia (A) Plain X-ray showing double bubble sign (arrow). (B) Contrast image demonstrating the dilated duodenum without spill (arrow). (C) Sonography image showing dilated duodenum (arrow).
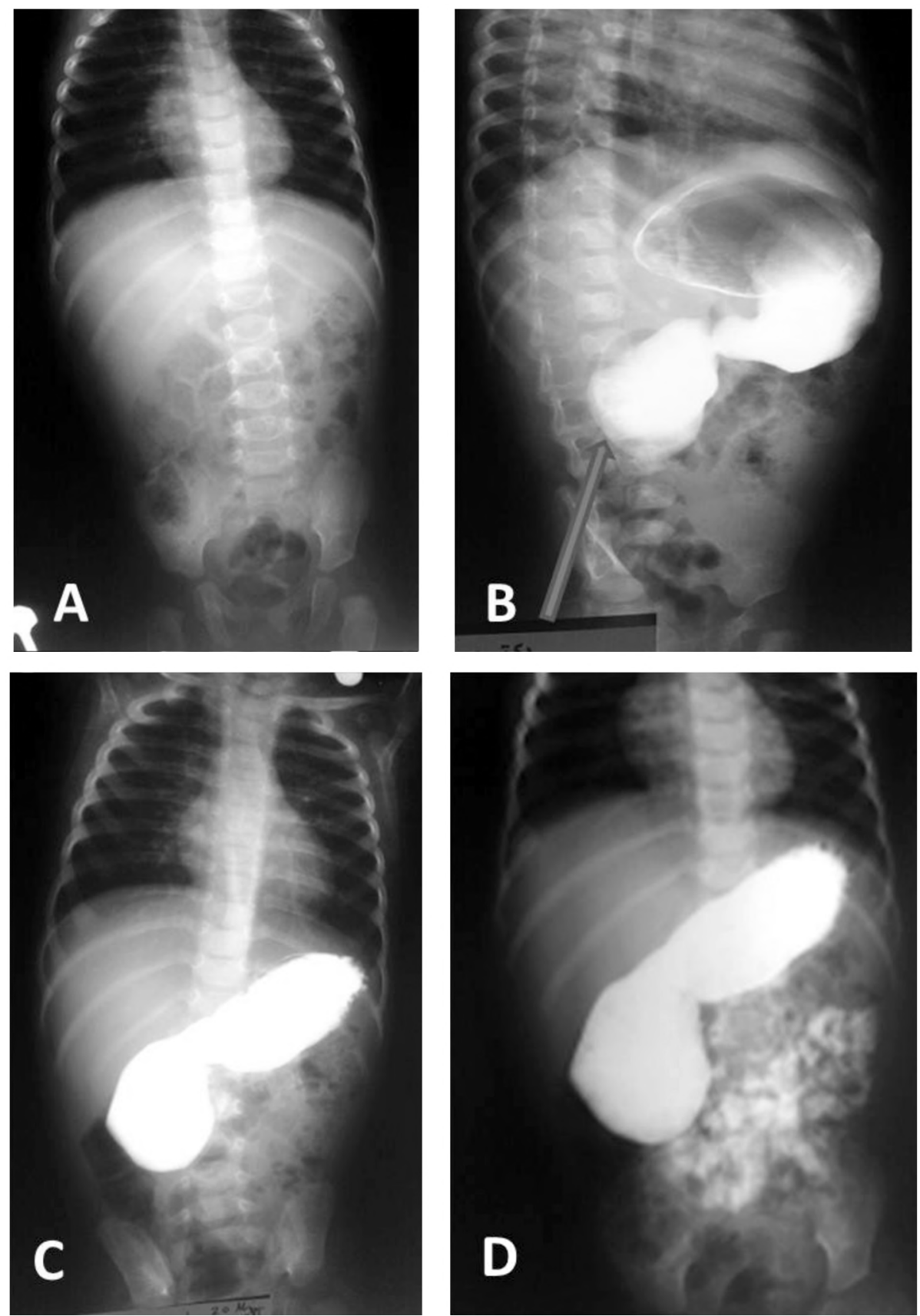

Fig. (6): A neonate with duodenal stenosis (A) Plain X-ray with non-significant findings $(\mathrm{B}, \mathrm{C}, \mathrm{D})$ Contrast meal and follow through serial images showing dilated duodenum (arrow) with minimal contrast spill. 

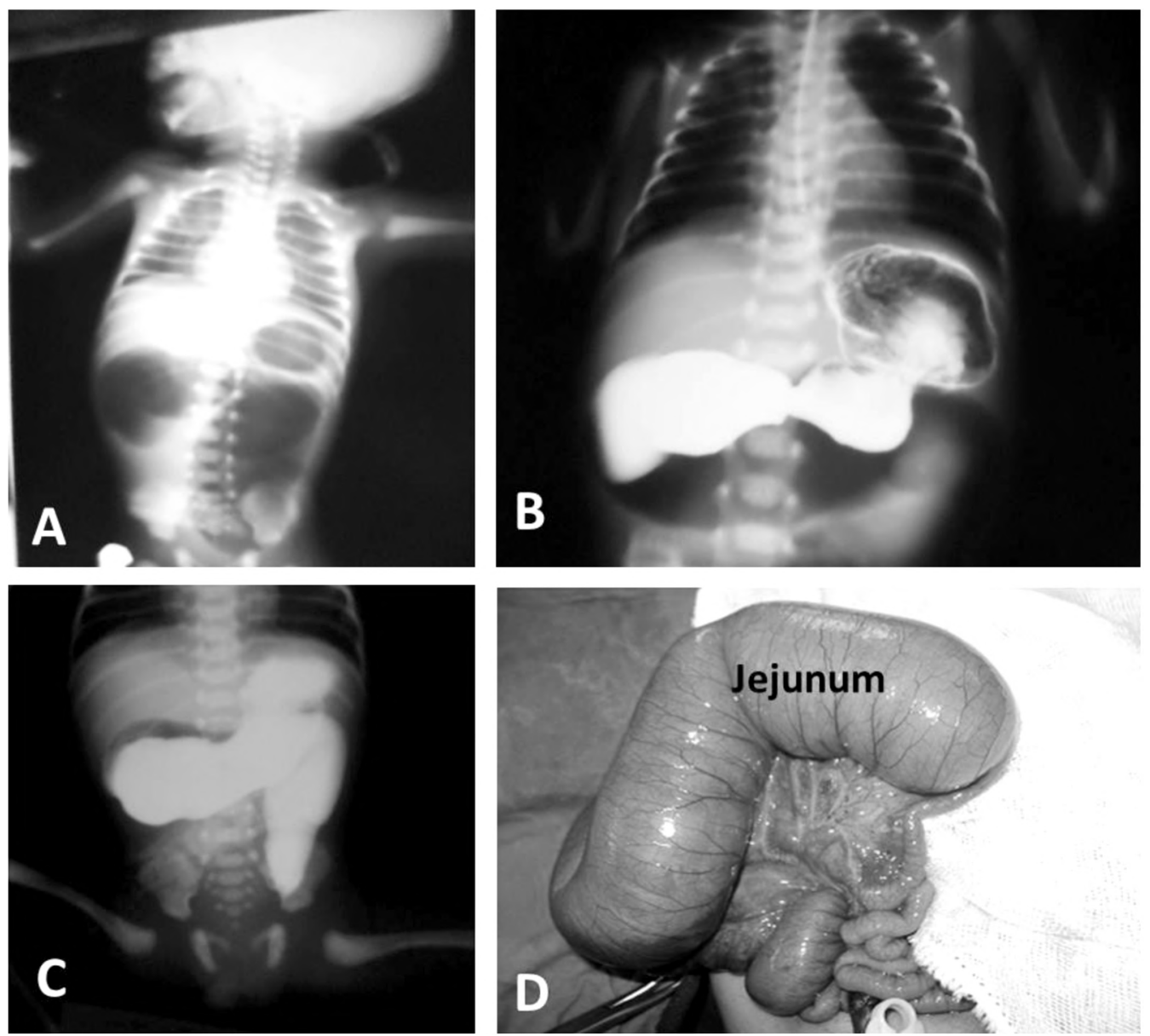

Fig. (7): A neonate with jejunal atresia (A) Plain-X-ray image showing markedly dilated proximal jejunal loops. $(B, C)$ Serial follow through images showing jeunal obstruction without spill of contrast beyond the jejunum. (D)Surgical photo confirm the diagnosis with dilated jejunum.
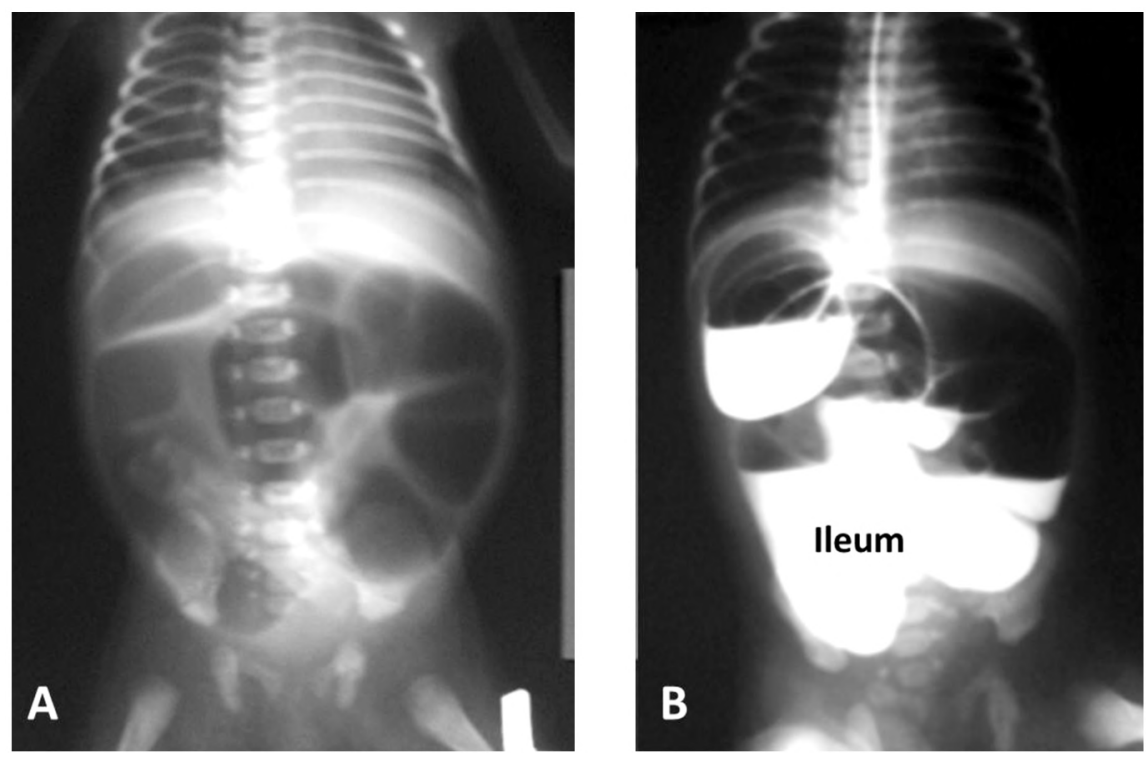

Fig. (8): A neonate with ileal atresia (A) Plain-X-ray image showing markedly dilated most of the small intestine. (B) Follow through image showing ileal obstruction without spill of contrast beyond the ileum. 

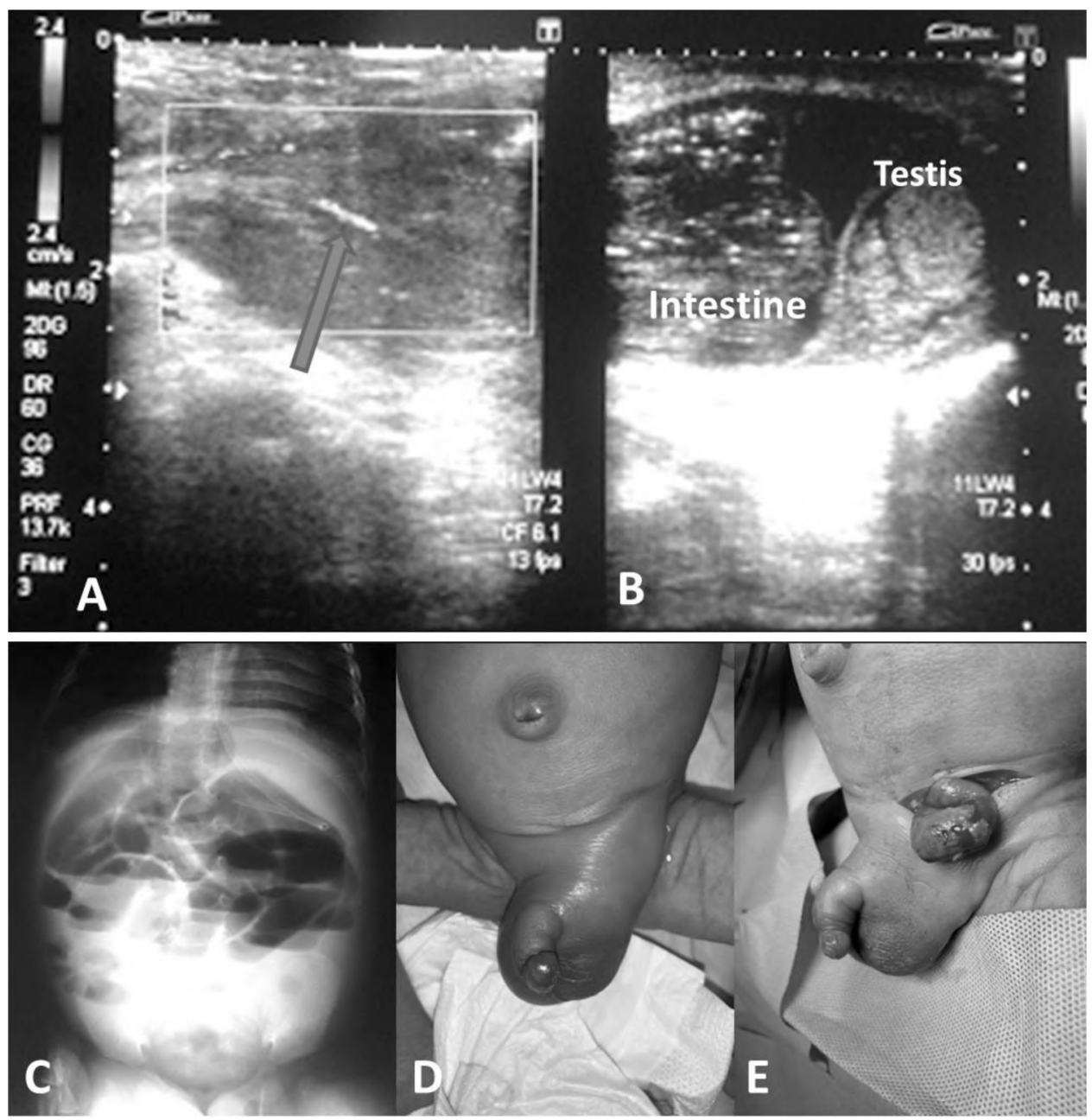

Fig. (9): A neonate with complicate inguinal hernia (A) Color Doppler imaging illustrating the vascularity of the hernia. (B) Sonography image showing the hernia above the testicle. (C) Plain-X-ray image showing intestinal. (D) Clinical photo of left inguinal hernia (E) Surgical photo of the complicated hernia.
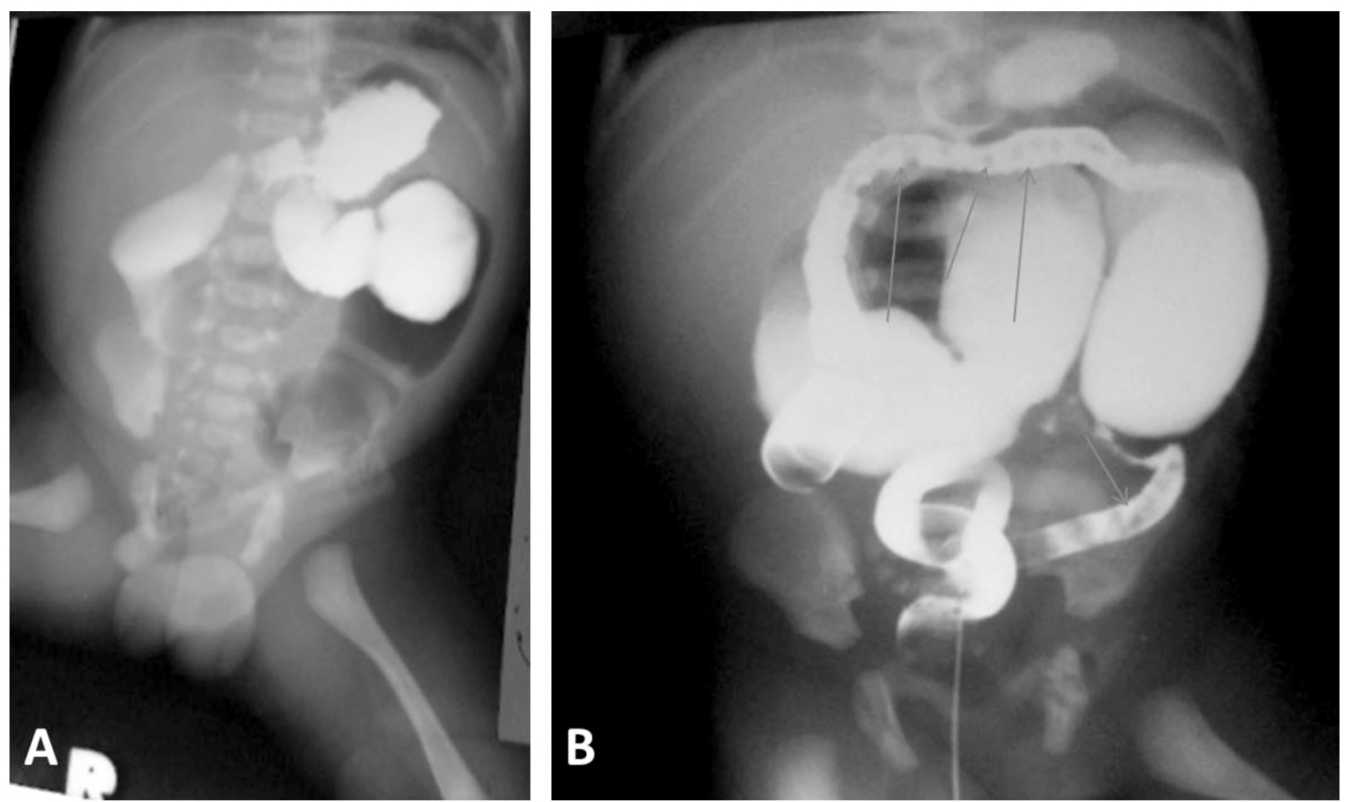

Fig. (10): A neonate with meconium ileus seocondary to plugs (A) Contrast follow through image showing the dilated small intestinal loops (B) Contrast enema showing multiple meconium plugs in the colon. 

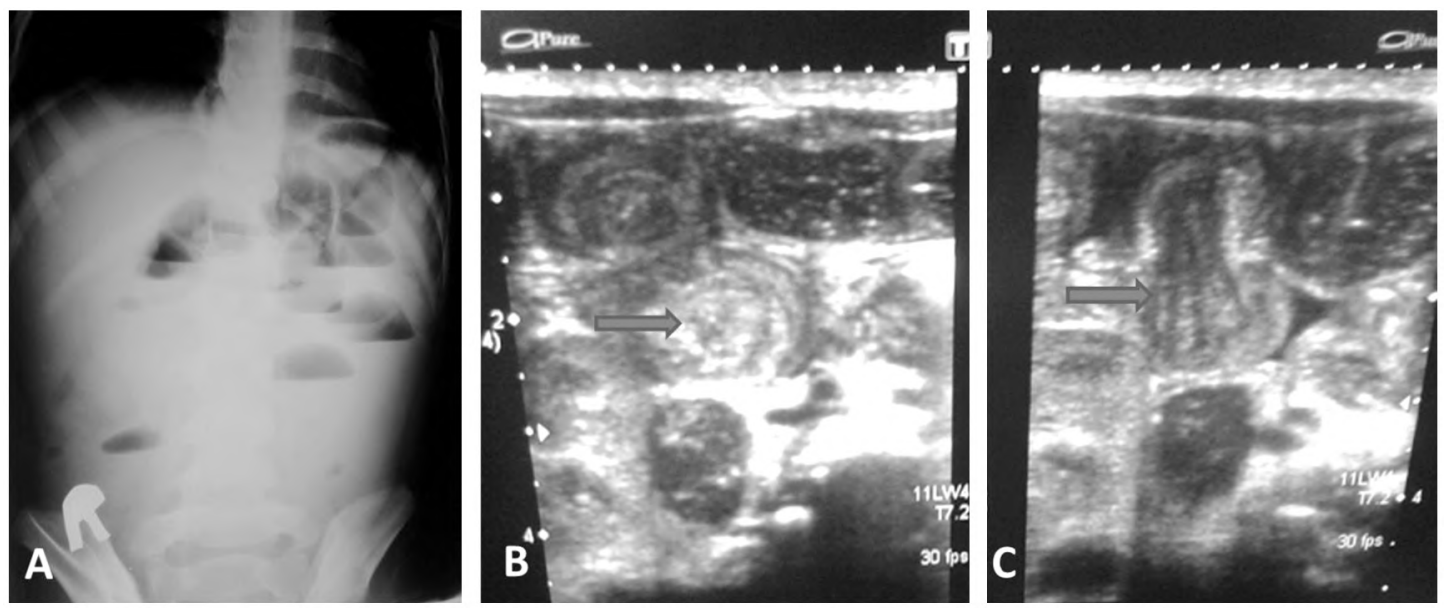

Fig. (11): A neonate with small intestinal intussusception (A) Erect abdominal X-ray showing small intestinal obstruction. (B, C) Sonography imaging showing short intussusception (arrows) with dilated proximal loops.
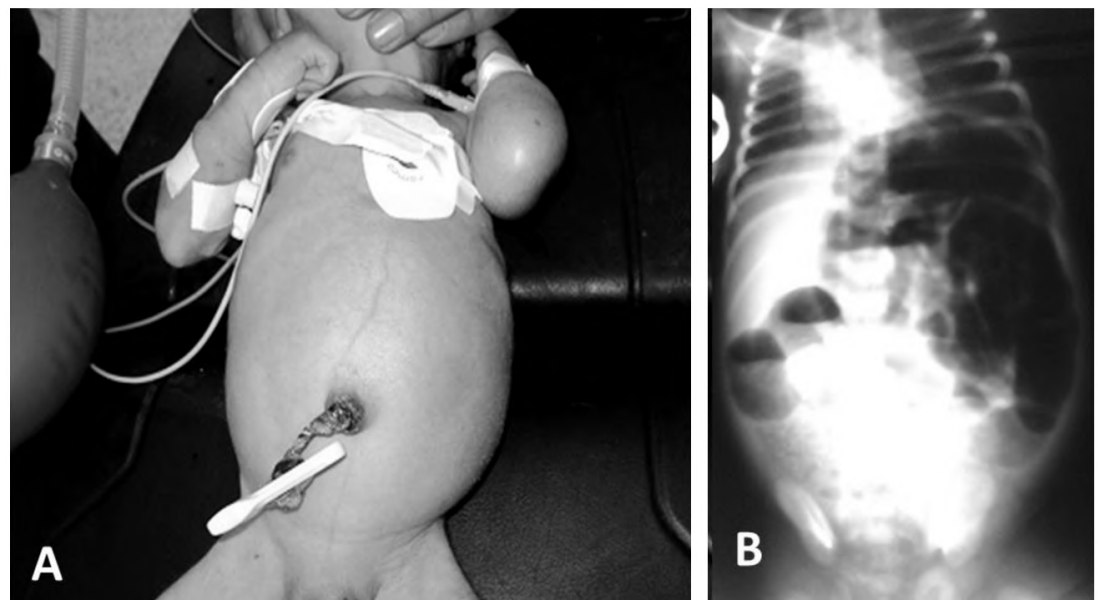

Fig. (12): A neonate with anal stenosis (A) Clinical photo showing distended abdomen. (B) Plain X-ray illustrating distended intestine by gases and loaded distal colon by fecal matter.

Table (1): Causes of bile stained vomiting diagnosed by imaging studies and operative procedures.

\begin{tabular}{lcl}
\hline Cause of vomiting & Number of patients & Operative procedure \\
\hline Necrotizing enterocolitis & 4 & Exploration with repair \\
Mid-gut volvulus & 5 & Untwisting of volvulus \\
Distal duodenal atresia & 3 & Diamond shaped duodeno-duodenostomy \\
Duodenal stenosis by incomplete web & 1 & Surgical repair \\
Jejunal atresia & 5 & Primary anastomosis with or without resection tapering \\
Ileal atresia & 4 & Anastomosis with or without resection \\
Congenital bands & 2 & Division of bands and bowel re-arrangement \\
Complicated inguinal hernia & 2 & Urgent hernia repair after assurance of contents viability \\
Meconium ileus with plugs & 2 & Frequent enema \\
Neonatal intussusception & 1 & Surgery \\
Iatrogenic umbilical hernia clamping & 1 & Exploration with surgical repair \\
Anal stenosis & 1 & Stage surgical repair \\
\hline
\end{tabular}

\section{Discussion}

Bile stained vomiting is frequently seen in neonatal period. It is an important and may be dangerous sign to deal with. Most of newborn come with this complaint are indicative of intestinal obstruction [19]. There are variable aetiologies for neonatal intestinal obstruction [20]. Congenital malformations such as atresia are commonly encountered. However rare congenital band or iatrogenic causes are also seen. Stabilization of the general condition of the patients must be done before further investigations. Imaging modalities have a major role in the diagnosis of the cause of bile stained vomiting in neonates [21]. 
Our study included 31 newborn with bile stained vomiting with surgical cause. Necrotizing enterocolitis is a very crucial disease especially if the patient came late because of the risk of perforation. Abdominal distension, pneumotosis intestinale and may be air under diaphragm are the most cardinal diagnostic signs [22]. Our study included 4 cases of necrotizing enterocolitis; one of them was very risky with evidence of perforation in X-ray, turbid peritoneal collection at sonography and confirmed at surgery. The utility of color Doppler sonography in cases of necrotizing enterocolitis was reported in many literatures [23-25]

This series included 5 cases with neonatal midgut volvulus. Actually Midgut volvulus in the newborn is a very important lesion because of vulnerability of blood supply of the wrapped parts of the intestine. Color Doppler sonography is the gold standard diagnostic method for midgut volvulus. Whirl pool sign and other Doppler stigmata are diagnostic [26,27]. Alehossein et al., [28] found 2 cases with midgut volvulus and diagnosed them by color Doppler sonography in his series for detection of causes of bilious vomiting in neonates. Malhotra et al., [29] reported in 6 cases with midgut volvulus in neonates with bilious vomiting.

Bile stained vomitus to occur; the obstruction must be beyond the papilla of Vater, Distal duodenal atresia is failure of recanalization of a part of the duodenum in fetal life. Duodenal atresia has the frequency of 1 in 7500 births. Neonate with distal duodenal atresia comes with bilious vomiting [30] Abdominal X-ray reveals the famous double bubble sign. On contrast imaging; no contrast could be passing beyond the duodenum. We found 3 cases with duodenal atresia in our work. Congenital duodenal stenosis is a variant of duodenal atresia. One case of congenital duodenal obstruction by incomplete web is seen in this study. The diagnosis is evident on contrast imaging. We observe that that the duodenum is dilated with minimal spill of contrast beyond this dilatation. Alehossein et al., [28] found two cases with duodenal atresia and two cases with duodenal web in his work examining neonates with bile stained vomiting.

Classically, when we think about a newborn with bile stained vomiting; we must suggest firstly jejuno-ileal atresia. It is may be due to placental vascular compromise [31]. Jejuno-ileal atresia is the most common reported cause of neonatal intestinal obstruction in literatures [32-34]. The clinical and radiological data are variable according to the type and level of atresia. Little abdominal distension and little air-fluid levels on erect abdomen X-ray is diagnostic of proximal jejunal atresia. With the increase of abdominal distension and increase of number air-fluid levels on plain films; a distal ileal level of obstruction is suggested. Small unused colon was seen on contrast enema. Jejuno-ileal atresia was reported in 9 cases of our study. Godbole et al., [35] reported 5 cases of intestinal atresia in his series examining neonates with bilious vomiting.

Neonatal intestinal obstructions caused by congenital bands are rare. The neonates come early with bile stained vomiting and abdominal distension. Sonography and plain X-ray revealed the intestinal obstruction; however without definite cause. On contrast imaging; the diagnosis may be mistaken with ileal atresia. Final diagnosis is always confirmed in these cases after surgical exploration. One case in our work was made the same scenario. Alehossein et al., [28] found one case of congenital band in neonates causing bilious vomiting. Aydin E [36] reported one case of congenital band as a rare cause of intestinal obstruction in new born.

Congenital inguinal hernia are commonly seen in pediatric age group; especially newborns. Sometimes; complicated inguinal hernia are the presenting symptoms especially with low socio-economic status. Two cases in our series came with inguinoscrotal swellings and bile stained vomiting. Plain $\mathrm{X}$-ray suggests intestinal obstruction. Viable irreducible inguinal hernia was found on Doppler sonography. On surgery one of them had perforation. Incarcerated inguinal hernia was reported in many series [37,38]. However; Khan et al., [39] reported a case of incarcerated inguinal hernia in neonate with perforation and fecal fistula.

Our study included 2 cases of intestinal obstruction by meconium ileus with plugs. The newborns presented with bile stained vomiting and abdominal distensions. Meconium ileus was frequently reported in literatures. It may be associated with cystic fibrosis. Godbole et al., [35] reported 2 cases of meconium ileus in his series examining neonates with bilious vomiting. Malhotra et al., [29] reported in 3 cases with meconium ileus in his work of neonatal bilious vomiting.

Intussusception is rarely occurring in neonatal period. Our series reported one case of intestinal obstruction by intussusception. The newborn came with bile stained vomiting. Sonography was diagnostic and confirmed and treated by surgery. Slam and his colleague [40] reported a case of multiple sequential intussusceptions in neonate. 
Iatrogenic neonatal intestinal obstruction may be caused by umbilical cord clamping on a nondiscovered small umbilical hernia. Actually; this is a catastrophic event to occur. Unfortunately we face with this case in our series in newborn with intestinal obstruction. This rare case was reported in literatures that advised doctors must take care during clamping of umbilical cord after delivery [41-43].

Anal stenosis was found in this work in one case. It is a rare congenital anomaly to be reported by Hamada et al., [44] in one case. This last author and his colleagues reviewed all Japanese literature in this subject.

There were few limitations in our study. Actually; the series was included small number of patients and did not cover all bile stained causes. The second limitation; we did not use CT or MRI do assess the patients. The third limitation; we didn't have prenatal data for the patients.

\section{Conclusion:}

Bile stained vomiting in neonates have variable causes. It usually denotes surgical problem and requires urgent surgical solution. Our study included necrotizing enterocolitis, midgut volvulus, distal duodenal atresia, duodenal stenosis, jejunal atresia, ileal atresia, congenital bands, complicated congenital inguinal hernias, meconium ileus, neonatal intussusception, iatrogenic clamping of umbilical hernia and anal stenosis. Imaging modalities were important to assess and diagnose these neonates before surgery.

\section{References}

1- COHEN L.: Bilious vomiting in the newborn. Adv. Pediatr. Res., 5: 13, 2018.

2- CARROLL A.G., KAVANAGH R.G., NI LEIDHIN C., CULLINAN N.M., LAVELLE L.P. and MALONE D.E.: Comparative Effectiveness of Imaging Modalities for the Diagnosis of Intestinal Obstruction in Neonates and Infants: A Critically Appraised Topic. Acad Radiol., 23 (5): 559-68, 2016.

3- VERMA A., NAIN RATTAN K. and YADAV R.: Neonatal intestinal obstruction: A 15 year experience in a tertiary care hospital. J. Clin. Diagn. Res., 10 (2): SC10-SC13, https://doi:10.7860/JCDR/2016/17204.7268, 2016.

4- SINGH V. and PATHAK M.: Congenital Neonatal Intestinal Obstruction: Retrospective Analysis at Tertiary Care Hospital. Journal of Neonatal Surgery, 5 (4): 49, https://. Doi: 10.21699/jns.v5i4.393, 2016.

5- BOROOAH M., NARANG G., MISHRA A., et al.: Bilious vomiting in the newborn period: Surgical incidence and diagnostic challenges Archives of Disease in Childhood, 95: A86, 2010.
6- BLUMER S.L., ZUCCONI W.B., COHEN H.L., SCRIVEN R.J. and LEE T.K.: The vomiting neonate: A review of the ACR appropriateness criteria and ultrasound's role in the workup of such patients. Ultrasound Q, 20: 79-89, 2004.

7- AMEH E.A. and NMADU P.T.: Intestinal atresia and stenosis: A retrospective analysis of presentation, morbidity and mortality in Zaria, Nigeria. West Afr. J. Med., 19 (1): $39-42,2000$.

8- KUMAR P., KUMAR C., PANDEY P.R. and SARIN Y.K.: Congenital Duodenal Obstruction in Neonates: Over 13 Years' Experience from a Single Centre. Journal of Neonatal Surgery, 5 (4): 50. https://DOI: 10.21699/ jns.v5i4.461, 2016.

9- S. VALL.S L., SERRA I., et al.: Imaging of non-neoplastic duodenal diseases. A pictorial review with emphasis on MDCT. Insights Imaging, 9: 121-35, 2018.

10- CHEN Q.J., GAO Z.G., TOU J.F., QIAN Y.Z., LI M.J., XIONG Q.X. and SHU Q.: Congenital duodenal obstruction in neonates: A decade's experience from one center. World J. Pediatr., 10 (3): 238-44, 2014.

11- RAHUL S.K., UPADHYAYA V.D. and KUMAR B. Malrotation and Midgut Volvulus associated with Asymptomatic Duplication Cyst of Jejunum. APSP J. Case Rep., 7 (4): 33. https:// doi:10.21699/ajcr.v7i4.447, 2016.

12- HAMIDI H., OBAIDY Y. and MAROOF S.: Intestinal malrotation and midgut volvulus. Radiol Case Rep., 11 (3): 271-4, 2016.

13- BAMIGBOLA K.T., NASIR A.A., ABDUR-RAHMAN L.O. and ADENIRAN J.O.: Complicated childhood inguinal hernias in UITH, Ilorin. Afr. J. Paediatr. Surg., Sep.-Dec., 9 (3): 227-30, 2012.

14- AKGUR F.M., TANYEL F.C., BUYUKPAMUKCU N. and HICSONMEZ A.: Anomalous congenital bands causing intestinal obstruction in children. J. Pediatr. Surg., 27: 471-3, 1992.

15- KLIEGMAN R.M.: Neonatal necrotizing enterocolitis: Bridging the basic science with the clinical disease. J. Pediatr., 117: 833-5, 1990.

16- SINGHI S.C., SHAH R., BANSAL A. and JAYASHREE M.: Management of a child with vomiting. Indian J. Pediatr., 80: 318-25, 2013.

17- PADMA R.: Neonatal gastrointestinal imaging. European Journal of Radiology, 60 (2): 171-86, 2006.

18- DURIE P.: Introduction to gastrointestinal imaging in pediatrics. In: Stringer D, ed. Pediatric Gastrointestinal Imaging. Philadelphia: BC Decker; 2-3, 1989.

19- KIMURA K. and LOENING-BAUCKE V.: Bilious vomiting in the newborn: Rapid diagnosis of intestinal obstruction. American Family Physician, 61 (9): 2791-8, 2000.

20- REYES H.M., MELLER J.L. and LOEFF D.: Neonatal intestinal obstruction. Clin. Perinatol., 16: 85-96, 1989.

21- VINOCUR D.N., LEE E.Y. and EISENBERG R.L.: Neonatal intestinal obstruction. Am. J. Roentgenol., 198 (1): 1-10, 2012.

22- THOMPSON A.M. and BIZZARRO M.J.: Necrotizing enterocolitis in newborns: Pathogenesis, prevention and management. Drugs, 68, 9: 1227-38, 2008. 
23- MERRITT C.R., GOLDSMITH J.P. and SHARP M.J.: Sonographic detection of portal venous gas in infants with necrotizing enterocolitis. Am. J. Roentgenol., 143 (5): 1059-62, 1984

24- FAINGOLD R., DANEMAN A., TOMLINSON G., et al.: Necrotizing enterocolitis: Assessment of bowel viability with color doppler ultrasound. Radiology, 235 (2): 587 94, 2005.

25- SILVA C.T., DANEMAN A., NAVARRO O.M., et al.: Correlation of sonographic findings and outcome in necrotizing enterocolitis. Pediatr. Radiology, 37 (3): 27482, 2007.

26- SHIMANUKI Y., AIHARA T., TAKANO H., et al.: Clockwise whirlpool sign at color Doppler US: An objective and definite sign of midgut volvulus. Radiology, Apr., 199 (1): 261-4, 1996.

27- CHAO H.C., KONG M.S., CHEN J.Y., LIN S.J. and LIN J.N.: Sonographic features related to volvulus in neonatal intestinal malrotation. J. Ultrasound Med., 19: 371-6, 2000.

28- ALEHOSSEIN M., ABDI S., POURGHOLAMI M., NASERI M. and SALAMATI P.: Diagnostic accuracy of ultrasound in determining the cause of bilious vomiting in neonates. Iran J. Radiol., 9 (4): 190-4, 2012.

29- MALHOTRA A., LAKKUNDI A. and CARSE E.: Bilious vomiting in the newborn: 6 years data from a Level III Centre. Journal of Paediatrics and Child Health, 46: 25961, 2010.

30- FONKALSRUD E.W., De LORIMAR A.A. and HAYS D.M.: Congenital atresia and stenosis of the duodenum. A review compiled from the members of the surgical section of the American Academy of Pediatrics. Pediatrics, 43: 79-83, 1969.

31- KOMURO H., AMAGAI T., HORI T., HIRAI M., MATOBA K., WATANABE M., et al.: Placental vascular compromise in jejuno-ileal atresia. J. Pediatr. Surg., 39 (11): 1701-5, 2004.

32- WAX J.R., HAMILTON T., CARTIN A., DUDLEY J., PINETTE M.G. and BLACKSTONE J.: Congenital jejunal and ileal atresia: Natural prenatal sonographic history and association with neonatal outcome. J. Ultrasound Med., 25 (3): 337-42, 2006.

33- OZTURK H., OZTURK H., GEDIK S., DURAN H. and ONEN A.: A comprehensive analysis of 51 neonates with congenital intestinal atresia. Saudi Med. J., 28 (7): 10504, 2007.

34- DALLA VECCHIA L.K., GROSFELD J.L., WEST K.W., RESCORLA F.J., SCHERER L.R. and ENGUM S.A.: Intestinal atresia and stenosis: A 25-year experience with 277 cases. Arch. Surg., 133 (5): 490-6, 1998.

35- GODBOLE P. and STRINGER M.D.: Bilious vomiting in the newborn: How often is it pathologic? J. Pediatr. Surg., 37: 909-11, 2002.

36- AYDIN E.: A rare cause of intestinal obstruction in a newborn: Congenital band compression. North Clin. Istanbul., 3 (1): 75-8, 2016.

37- AMEH E.A.: Morbidity and mortality of inguinal hernia in the newborn. Niger. Postgrad. Med. J., Dec., 9 (4): 233-4, 2002.

3 8- SHUN A. and PURI P.: Inguinal hernia in the newborn A 15-year review. Pediatr. Surg. Int., e3 (2-3): 156-157, 1988.

39- KHAN T.R., MALETHA M. and TANDON R.: Neonatal incarcerated inguinal hernia with spontaneous scrotofecal fistula. Journal of Pediatric Surgery, 44 (9): 18467, 2009.

40- SLAM K.D. and TEITELBAUM D.H.: Multiple sequential intussusceptions causing bowel obstruction in a preterm neonate. Journal of Pediatric Surgery, 42 (7): 1279-81, 2007.

41- CIZMECI M.N., KANBUROGLU M.K., AKELMA A.Z. and TATLI M.M.: Do not overlook an umbilical cord hernia before clamping. Eur. J. Pediatr., 172: 1139, 2013.

42- GASPARELLA M., ZANATTA C., FERRO M., MARZARO M., BENETTON C., et al.: Iatrogenic Intestinal Laceration Secondary to Clamping of Unrecognized Umbilical Cord Hernia: A Case Report. J. Women's Health Care, 3: 177, 2014

43- ASABE K., OKA Y., KAI H. and SHIRAKUSA T.: Iatrogenic ileal perforation: An accidental clamping of a hernia into the umbilical cord and a review of the published work. J. Obstet. Gynaecol. Res., 34 (4 Pt 2): 619-22, 2008 .

44- HAMADA Y., MORI T., TANANO A., et al.: Anorectal Stenosis in a Neonate: Report of a Case and Review of the Japanese Literature. Surg. Today, 26: 814, 1996. 


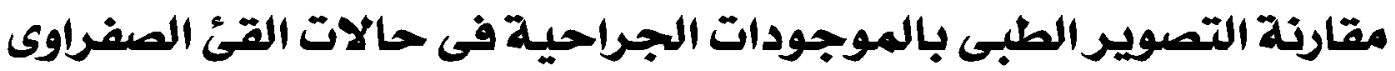 في الآطفال حديثى الودات الودرة}

وقد هدفت الدراسة لتقييم آهمية التصوير الطبى لحالات القئ الصفراوى فى الآطفال حديثى الولادة وترابطها بالموجودات الجراحية. ولقد إثتملت الدراسة على الآطفال حديثى الولادة والذين كانوا يعانهن من قئ صفراهى وله سبب جراحى. ولقد وجد عدد الم من الآطفال حديثى الولادة والذين يعانون من القئ الصفراوى . وقد تم فحص هؤلاء الآطفال في قسم الآطفال ووحدة

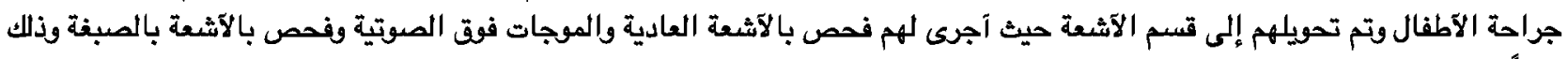
طبقاً لحالة المريض.

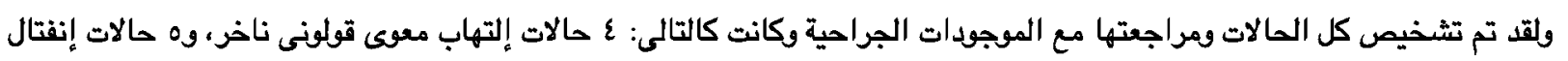

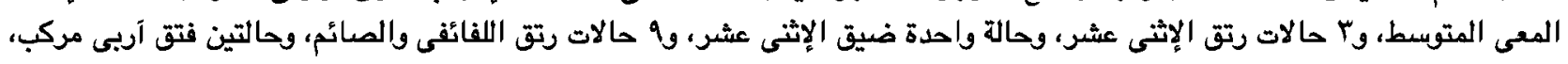

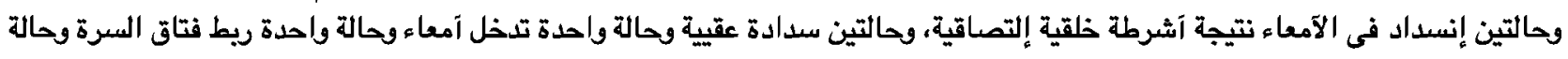

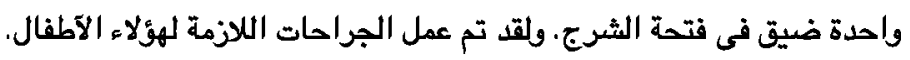

ولقد آستنتج من هذه الدراسة الآهمية القصوى اللتصوير الطبى في معرفة آسباب القئ الصفراوى في الآطفال حديثى الولادة لما فيها من

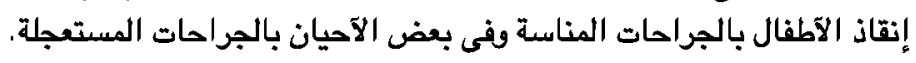

